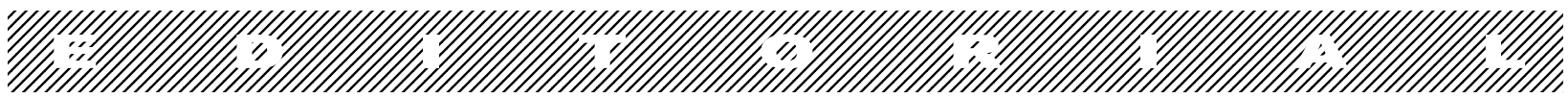

\title{
Periódicos impressos ou eletrônicos?
}

No momento em que iniciamos nosso sexto ano de publicação - e apresentamos nosso novo formato e identidade visual -, a revista Estudos de Psicologia (Natal) passa a ser acessível eletronicamente, através do Scientific Eletronic Library Online - SciELO (htpp://www.scielo.br/epsic-p).

Essa conjunção de eventos constitui-se, sem dúvida, em motivo de enorme satisfação para nós, tanto pela visibilidade que um serviço deste tipo oferece, quanto pelo reconhecimento da qualidade da nossa publicação.

Mas, ao mesmo tempo, nos faz indagar sobre o destino do meio impresso diante do eletrônico.Estaríamos caminhando, inexoravelmente, para o fim dos periódicos impressos e - estendendo um pouco mais o raciocínio, dos próprios livros (cedendo lugar para os $e$-books)?

$\mathrm{O}$ aspecto mais crucial da publicação eletrônica diz respeito à acessibilidade. Levantamentos realizados (King \& Tenopir, 1998) nos dão conta de que um artigo publicado em um periódico internacional alcança um número médio de 500 a 1500 leituras/consultas, conforme a área do conhecimento envolvida, ao longo de sua "vida útil"1.

Não nos parece desarrazoado supor que existam padrões diferenciados quanto ao comportamento do pesquisador brasileiro com relação à média internacional, quanto ao acesso à literatura especializada, no Brasil e nos países produtores de conhecimento. Se tem procedência essa suposição, uma possível decorrência seria a de que a média de alcance de um artigo publicado em um periódico nacional é menor que aquela levantada internacionalmente.

Se recorrermos aos dados estatísticos do SciELO, verificaremos que existem artigos na área das Ciências Humanas com mais de 1000 acessos, somente computados os textos completos ${ }^{2}$. Existem fascículos no SciELO que atingem consultas na ordem de 14.000 acessos (até abril de 2001), o que, certamente, é uma marca espantosa ${ }^{3}$.

Embora o meio eletrônico ainda seja bastante seletivo ${ }^{4}$, parece inquestionável que ele possibilita uma disseminação do conhecimento em escala muito mais larga do que os meios impressos.

A maior acessibilidade ao conhecimento põe algumas questões interligadas: analogamente ao que ocorre nos meios impressos, o acesso deve, de alguma forma, ser taxado? Se a resposta for negativa, quem arcaria com os custos de uma publicação eletrônica?
Estas indagações nos conduzem às antigas (mas sempre atuais) discussões sobre as finalidades do trabalho científico e a propriedade do conhecimento ${ }^{5}$.

Não se pode negar que a questão dos custos é séria e, talvez, não comporte soluções fáceis. Publicar uma revista unicamente eletrônica pode reduzir consideravelmente os custos com relação ao meio impresso (além de uma nãodesprezível contribuição para a diminuição da devastação das nossas florestas...). Contudo, os custos permanecem e, sem contar com financiamentos de agências de fomento (como o Programa de Apoio a Publicações Científicas/Auxílio Editoração, do CNPq/Finep), talvez seja virtualmente impossível a sua manutenção. Por seu turno, a manutenção de uma forma impressa paralela à eletrônica poderia viabilizar o funcionamento da publicação.

Contudo, os custos envolvidos no precesso editorial têm levado muitas editoras ou a não disponibilizar a íntegra dos textos eletronicamente, ou cobrado pelos serviços.

É impossível prever qual resolução terá essa questão, mas a possibilidade aberta pelos meios eletrônicos na direção da democratização do conhecimento é uma perspectiva tão estimulante, que não pode ser desprezada.

Ao lado de propostas bem sucedidas como é o caso do SciELO, algumas experiências em nível internacional têm surgido, almejando o acesso irrestrito às íntegras dos tex$\operatorname{tos}^{6}$.

Talvez a mais conhecida delas - uma experiência que teve início em 1991! - é o Los Alamos Physics Archive (http:/ /xxx.lanl.gov), contando com cerca de 100.000 artigos autoarquivados pelos próprios autores no campo da Física. É bem verdade que tais experiências comportam trabalhos de qualidades diversas: uma parte considerável delas são as chamadas "pre-prints", textos provisórios colocados pelo autor para debate na comunidade científica, antes de adquirir a forma definitiva.

Experiências como a de Los Alamos estimulou diversas iniciativas para uma publicização maior do procedimento de auto-arquivamento ${ }^{7}$, inclusive, e esse é o aspecto mais importante, de artigos revisados por pares. No ano de 1999, um encontro de grande porte que estabele a Santa $\mathrm{Fe}$ Convention of the Open Archives, um passo na direção de uma proposta de criação de uma rede mais ampla de textos e sistemas interligados. 
Mas, para além da possibilidade de disponibilizar a íntegra dos textos revisados por pares, a introdução dos meios eletrônicos na editoração pode representar uma mudança substancial nas formas mesmas de revisão: existem alguma experiências em que pre-prints são publicados em sites restritos para revisão voluntária do grupo de consultores da revista, o que pode significar contribuições bastante significativas de um enorme grupo de colegas. Pensando um pouco mais além, não seria possível imaginar um artigo que nunca ficasse na forma definitiva, isto é, que sempre estivesse aberta à revisão pelo seu autor, em resposta a avaliação de seus pares ou à incorporação de novos dados? Ou ainda - uma preocupação de muitos pesquisadores - como acrescentar velocidade ao processo de publicação de resultados de pesquisa? A publicação eletrônica não poderia ser uma possibilidade? ${ }^{8}$

Essas são algumas das infindáveis questões - e desafios - que a veiculação eletrônica das revistas coloca. E são questões para as quais o debate é urgente - sob risco de sermos atropelados pelos acontecimentos.

Neste fascículo, contamos com onze artigos, com uma ampla gama de temáticas e abordagens teóricometodológicas. Sandra Álvares, Grauben Assis, Isabel Esteves e M. Elizângela Sampaio apresentam um estudo sobre discriminações condicionais em crianças; Anna C. Lo Bianco aborda o funcionamento interpretante do aparato psíquico; Jorge Sarriera, Marli Silva, Cristina, Kabbas e Vanessa Lòpes discutem a formação da identidade ocupacional em adolescentes; Mônica Magalhães e Jairo Borges-Andrade enfocam a avaliação no diagnóstico de necessidades de treinamento; Ana C. Brandão e Alina Spinillo apresentam um trabalho sobre produção e compreensão de textos; Marinalva Oliveira e Emmanuel Tourinho estudam o desempenho de crianças em problemas aritméticos; Abelardo Silva e Hartmut Günther pesquisam as relações de ajuda entre usuários de ônibus; José Célio Freire apresenta uma original análise da temporalidade na obra proustiana; Mário C. Ferreira e Ana Magnólia Mendes apresentam um estudo sobre a relação prazer-sofrimento no atendimento ao público; Andréa Zanella e Renata Pereira estudam a constituição de grupos, e Paula Fernandes e Elisabete Abib de Souza discutem procedimentos educativos na epilepsia infantil.

Uma palavra final de agradecimento aos nossos autores que, desde o início, têm nos prestigiado com suas colaborações - e aos nossos leitores, que têm viabilizado o êxito deste empreendimento.

\section{Referência}

King, D. W., \& Tenopir, C. (1998). A publicação de revistas eletrônicas: economia da produção, distribuição e uso. Ciência da Informação, 27(2), 176-182.

Oswaldo H. Yamamoto Editor

\section{Notas}

1 Um outro dado interessante diz respeito ao número médio de leitura de artigos por parte de pesquisadores vinculados à academia: 188 artigos/ano.

${ }^{2}$ No caso das revistas de Psicologia no SciELO, os artigos mais visitados contabilizam pouco menos de 400 acessos (textos completos) até o mês de abril de 2001

${ }^{3}$ Para um padrão de comparação, uma revista exclusivamente online britânica, da área das Ciências Sociais, a Sociological Research Online (http://www.socresonline.org.uk), mantida pela Universidades de Surrey e Stirling, pela British Sociological Association e pela SAGE Publications Ltd., e indexada no Institute for Scientific Information (ISI), atinge médias diárias de cerca de 5.000 acessos.

${ }^{4}$ Existem dois ângulos a considerar nessa questão. De uma parte, a óbvia constatação de que o acesso ao meio eletrônico demanda um conjunto de condições (equipamento, linha telefônica, acesso a um provedor), absolutamente distantes das possibilidades financeiras da maior parcela da população do terceiro mundo. Mas existe uma outra questão mais séria: na Tenth International Conference of Science Editors, realizado entre os dias 27-30 de agosto de 2000 no Rio de Janeiro, W. Wayt Gibbs, colaborador da revista Scientific American apresentou dados de uma pesquisa que mostram que a Internet está promovendo uma nova divisão entre as nações produtoras e 
consumidoras de conhecimento. Segundo Gibbs, com o advento dos meios eletrônicos de disseminação do conhecimento, diversas nações do terceiro mundo passaram a ter mais visibilidade do mundo científico. Como contraponto, entretanto, o fosso entre esse conjunto e as demais nações aumentou de maneira brutal, dificultando ainda mais o já restrito acesso das nações mais pobres (sobretudo, as do continente africano) ao conhecimento científico produzido no hemisfério norte.

${ }^{5}$ No final do mês de abril, foi veiculada uma notícia acerca de um movimento dos pesquisadores britânicos contra a retenção dos direitos autorais dos papers por parte dos periódicos, ameaçando de boicote - o que poderia levar as publicações à morte por "inanição". Trata-se de mais um desdobramento da questão que estamos abordando. ${ }^{6}$ Algumas inciativas importantes, sem embargo das limitações para acesso, são os portais Periódicos, mantido pela CAPES (http://www.periodicos.capes.gov.br), e ProBE (Programa Biblioteca Eletrônica - http://www.usp.br/ sibi). O primeiro fornece, dentre outros serviços, acesso à base de dados PsycINFO e a quatro dezenas de títulos editados da American Psychological Association

${ }^{7}$ O sistema de auto-arquivamento de artigos pelos autores é recebe a denominação internacional de $e$-print systems. Diversos desses sistemas de Open Archives já estão disponíveis, além do pioneiro Los Alamos. Entre eles, o CogPrints (http://cogsci.soton.ac.uk), baseado na Universidade de Southampton (Reino Unido), com foco em trabalhos na área da Psicologia, Lingüística e Neurociências e o PubMed Central (http://nih.gov/welcome/ director/pubmedcentral/pubmedcentral.htm), com trabalhos na área da Saúde.

${ }^{8}$ Recentemente, uma colega, Ana Maria Nicolaci da Costa, da PUC-RJ, colocou em debate essa questão em um grupo de discussões composto por pesquisadores da área da Psicologia, especialmente preocupada com a caducidade de estudos que estava conduzido acerca dos impactos gerados pelo uso da Internet, se publicada através dos procedimentos normais nos periódicos impressos. Curiosamente, nessa direção, foi desencadeada uma experiência denominada Revista Eletrônica Psicologia para a América Latina, sediada no México, e contando com equipes no Brasil, Uruguai, Argentina e Chile. Trata-se de uma experiência bastante recente, que necessita de acompanhamento. O editor geral é Marco Eduardo Murueta (murueta@ servidor.unam.mx) e o brasileiro, Sérgio A. Leite (sasleite@uol.com.br). 